\title{
Effects of a cancer genetics education programme on clinician knowledge and practice
}

\author{
K R Blazer, M Grant, S R Sand, D J MacDonald, G C Uman, J N Weitzel
}

J Med Genet 2004;41:518-522. doi: 10.1136/jmg.2004.018234

\begin{abstract}
Background: Many clinicians lack adequate knowledge about emerging standards of care related to genetic cancer risk assessment and the features of hereditary cancer needed to identify patients at risk.

Objective: To determine how a clinical cancer genetics education programme for community based clinicians affected participant knowledge and changed clinical practice.

Methods: The effects of the programme on participant knowledge and changes in clinical practice were measured through pre and post session knowledge questionnaires completed by 710 participants and practice impact surveys completed after one year by 69 out of 114 eligible annual conference participants sampled.

Results: Respondents showed a $40 \%$ average increase in specific cancer genetics knowledge. Respondents to the post course survey reported that they used course information and materials to counsel and refer patients for hereditary cancer risk assessment $(77 \%)$, shared course information with other clinicians (83\%), and wanted additional cancer genetics education (80\%).

Conclusions: There was a significant immediate gain in cancer genetics knowledge among participants in a targeted outreach programme, and subset analysis indicated a positive long term effect on clinical practice. Clinician education that incorporates evidence based content and case based learning should lead to better identification and care of individuals with increased cancer risk.
\end{abstract}

$\mathrm{T}$ he ongoing discovery of genes associated with cancer and diagnostic tests to predict cancer risk brings new hope for the early detection or prevention of disease. While only $5-10 \%$ of cancers are associated with highly penetrant single gene traits, this translates to hundreds of thousands of cancer cases attributable to hereditary predisposition. Identifying those at increased risk through genetic cancer risk assessment allows for more effective application of potentially life saving surveillance or preventive measures, and may improve the quality of life for individuals and families at risk. ${ }^{1-7}$

The risk assessment process involves cancer risk genetic counselling and diagnostic or predictive germline genetic testing when indicated, and is now considered standard care for such syndromes as multiple endocrine neoplasia types I and II, familial adenomatous polyposis, and von HippelLindau disease, as well as for disorders seen more commonly in clinical practice, such as hereditary breast and ovarian cancer syndrome and hereditary non-polyposis colorectal cancer. ${ }^{8-14}$

While physicians are increasingly aware of advances in genetic technology, many are not adequately trained to recognise the features of hereditary cancer predisposition that warrant referral for risk assessment, and some do not view this service as a health care priority because they are unaware of the potential benefits of genetic testing to the patient. ${ }^{15-21}$ Educational resources, professional practice guidelines, and a robust literature on practical issues in cancer risk assessment are emerging, ${ }^{92-26}$ but limited knowledge among primary care physicians and other healthcare providers who influence patient referrals remains a significant barrier to appropriate utilisation of cancer risk assessment services. ${ }^{27-31}$

Targeted education to clinicians should facilitate the integration of genetic screening services into clinical practice, ${ }^{223233}$ but promoting cancer genetics education is a challenge, due in part to the complex health and social issues related to hereditary disease, to the rapidly evolving body of knowledge about genetic risk assessment and high risk management, and to the constraints on physician time for continued education. ${ }^{34}{ }^{35}$ In 1996, the City of Hope Departments of Clinical Cancer Genetics and Nursing Research and Education joined up, to establish the City of Hope Cancer Genetics Education Program (CGEP). The objective of the first phase of this programme was to confer screening level competence (ability to recognise key features associated with potential hereditary cancer predisposition adequately to refer at risk patients for cancer risk assessment) to community based physicians and other health care professionals through progressive lectures accredited for continuing medical education at regional health centres as well as annual full day conferences. This report describes the outcomes of the first five years of educational outreach by the CGEP.

\section{METHODS}

The project and study protocol were approved by the City of Hope Institutional Review Board (IRB\#00081). The core curriculum was developed by a multidisciplinary team from the Clinical Cancer Genetics and Nursing Research Education faculty, incorporating key elements of the cancer genetics curriculum published by the American Society of Clinical Oncologists, ${ }^{36} 37$ periodic reviews of the medical literature, scientific meeting proceedings, and practical clinical experience from the Cancer Screening and Prevention Program (a clinical cancer genetics services network). Topic domains of the CGEP core curriculum are listed in table 1. Detailed descriptions of the CGEP curriculum development and programme implementation are published elsewhere. ${ }^{38}$

Modules focusing on a specific topic (for example, hereditary breast and ovarian cancer) with illustrative case based scenarios and evidence based information on high risk surveillance and management options were delivered by CGEP faculty as one hour lectures at community hospital grand rounds or similar educational venues. In addition, six annual full day conferences providing in depth coverage of a specific topic in clinical cancer genetics were conducted at the

Abbreviation: CGEP, City of Hope Cancer Genetics Education Program 
Table 1 Cancer genetics education programme curriculum topic areas

\begin{tabular}{l}
\hline Cancer genetics education program (CGEP) topic domains \\
\hline Principles and practice of genetic cancer risk assessment* \\
Basic mechanisms of heredity, mutations, and carcinogenesis \\
Hereditary breast and ovarian cancer* \\
Hereditary forms of colorectal cancer* \\
Management of patients with inherited susceptibility to cancer* \\
Ethical, legal, social, and insurance issues related to cancer \\
predisposition testing* \\
Methods of detecting genetic mutations* \\
Cancer associated genodermatoses, including melanoma and basal cell \\
carcinoma \\
Hereditary syndromes that present as cancer in childhood \\
Genetic testing and screening for multiple endocrine neoplasia \\
Rare hereditary disorders associated with cancer susceptibility \\
*Most frequently requested domains for one hour continuing medical \\
education lectures
\end{tabular}

cancer centre. Full day conference curricula used elements of the core curriculum with additional lectures by nationally recognised cancer genetics professionals, and included case based presentations by community based physicians, and workshops for interactive learning. A list of the programme's full day conferences and attendance summaries is included in table 2. Educational offerings were promoted by direct and electronic mail through the institution's established continuing medical education programme, collaboration with regional health care and community based organisations (Kaiser Permanente of Southern California, the American Cancer Society, The Wellness Community), and through focused marketing to geographically underserved regions in Northern California and Arizona that were part of a telemedicine outreach project of the established Cancer Screening and Prevention Program satellite and telemedicine outreach sites. Course descriptions and online registration were also available on the department website (www.cityofhope.org/ccgp).

An interdisciplinary CGEP Advisory Committee, comprising professionals in social services, bioethics, law, medical education, and marketing, and representatives from the American Cancer Society and Wellness Community, met quarterly to provide guidance in curriculum development and updating, marketing, and evaluation of outcomes.

\section{Measuring outcomes}

Knowledge questions derived from the course curriculum were developed and periodically updated to reflect scientific advances and improve content validity. Surveys consisting of 10 questions for one hour lectures and 30 questions for full day conferences were created from a bank of 127 items. The questions measured knowledge of key concepts in applied genetics, such as recognising inheritance patterns and clinical features of specific hereditary cancer syndromes and questions on syndrome specific surveillance and management strategies. Question construction was examined and revised in consultation with a psychometrician ( $\mathrm{G} \mathrm{C} \mathrm{Uman).} \mathrm{Item}$ difficulty and discrimination indices were calculated, and distractor analysis was conducted on multiple choice questions. At the time of analysis the 127 questions in the item bank had an average difficulty of 0.64 , slightly higher (easier) than the ideal average difficulty of 0.50 . Ten questions that were administered to the most participants $(n=180)$ had an internal consistency reliability of coefficient $\alpha=0.65$ (acceptable for continuing medical education or education research, but not for credentialling standards). The discrimination index for those questions ranged from 0.16 to 0.43 , and averaged 0.31. A cover sheet requested basic demographics such as profession (MD, registered nurse, etc.), areas of practice specialty and professional focus (clinical, research, academic); personal identifiers were not requested.

Knowledge surveys were administered to participants in randomly selected community hospital one hour lectures sampled during years two to five of the programme and to all participants of each full day conference. Surveys were administered before lectures and repeated after the sessions to measure immediate postintervention knowledge gain. Standard continuing medical education evaluations were collected and summarised to measure participant feedback on presentations and perceived value and utility of the information provided.

A postcourse practice survey elicited how clinicians applied cancer genetics information to their practices one year after attending a full day cancer genetics conference. The survey requested professional demographic information but was otherwise anonymous, and contained nine items about the applicability and utility of conference information in clinical practice and to determine participants' interest in continued cancer genetics education. Logistical and privacy challenges limited opportunity for long term follow up of participants in community hospital grand rounds continuing medical education lectures (contact information for participants at community hospital continuing medical education lectures was not available to CGEP faculty staff). We therefore piloted the practice outcomes survey on 114 eligible participants from the 2002 CGEP full day conference who stated that they were clinical practitioners. The survey was disseminated by mail 11 months after the conference. A modest incentive of a $\$ 5.00$ coffee coupon was included in all surveys. In an adaptation of Dillman's methodology, ${ }^{39}$ a second mailing was sent six weeks after the initial mailing to increase response rate. The second mailing also included a one page fact sheet

Table 2 Topics and attendance summaries of cancer genetics education programme annual full day conferences

\begin{tabular}{|c|c|c|}
\hline Title & Date & $\begin{array}{l}\text { Number of } \\
\text { attendees }\end{array}$ \\
\hline $\begin{array}{l}\text { Breast and ovarian cancer risk assessment: genetic } \\
\text { technologies and clinical practice }\end{array}$ & 8 October, 1997 & 80 \\
\hline $\begin{array}{l}\text { Assessing your patient's risk for breast and ovarian cancer: } \\
\text { genetic technologies and clinical practice }\end{array}$ & 29 May, 1998 & 100 \\
\hline $\begin{array}{l}\text { Emerging genetic technologies in gastrointestinal cancers: } \\
\text { a multidisciplinary approach for the clinician }\end{array}$ & 23 January, 1999 & 85 \\
\hline $\begin{array}{l}\text { Hereditary cancer syndromes: are your patients at risk? genetic } \\
\text { technologies and risk management in the new millennium }\end{array}$ & 26 February, 2000 & 170 \\
\hline $\begin{array}{l}\text { Advances in cancer screening and prevention: practical } \\
\text { applications across the full spectrum of risk }\end{array}$ & 17 February, 2001 & 221 \\
\hline $\begin{array}{l}\text { Gastrointestinal cancers: critical advances in risk assessment, } \\
\text { screening, and management }\end{array}$ & 23 March, 2002 & 150 \\
\hline
\end{tabular}


summarising guidelines for referral for genetic cancer risk assessment to reinforce clinician learning.

\section{RESULTS}

\section{Knowledge outcomes}

Seven hundred and ten fully completed presession and postsession knowledge surveys were available for analysis The proportion of registered clinicians who completed preliminary surveys fully was greater from full day conferences than that from one hour grand rounds lectures (table 3). Approximately $88 \%$ of full day conference participants practiced primarily in a clinical setting, and $12 \%$ were from a primarily academic or research setting. The number of participants with complete data sets and increment in knowledge improvement is summarised in table 3. Postcourse test scores demonstrated a significant overall increase in participant knowledge in both settings: $48 \%$ at one hour seminars $(\mathrm{p}<0.001) ; 38 \%$ at full day conferences $(\mathrm{p}<0.001)$. Of physicians who responded to knowledge surveys, 39\% were primary care physicians, $14 \%$ were gynecologists, $12 \%$ were oncologists, and $11 \%$ were gastrointestinal specialists; the remaining $24 \%$ of physician respondents did not indicate their specialties. The knowledge of all physicians who provided their specialty information increased significantly $(\mathrm{p}<0.001)$, but no particular specialty outperformed any other at precourse or postcourse testing $(\mathrm{p}=0.383)$.

Though not statistically significant, baseline (presession) scores were higher across disciplines among participants in full day conferences (48\% correct answers) compared with those from one hour lectures (40\% correct answers), possibly reflecting selection for clinicians interested or involved in cancer genetics among attendees of full day conferences. The proportional postsession knowledge gain was similar for both one hour lecture and full day conference participants. Analysis of scores by clinical discipline (MDs, registered nurses, and genetic counsellors) demonstrated that the three clinical disciplines began with significantly different levels of cancer genetics knowledge, as shown in fig $1 \quad(p \approx 0.001)$. Baseline knowledge was greatest among genetic counsellors, who have focused training in general genetics (62\% correct answers at baseline among genetic counsellors, compared with $46 \%$ for MDs and $38 \%$ for registered nurses). A significant improvement in postsession knowledge was realised across all three disciplines.

Long term follow up survey of 114 clinician participants of the 2002 CGEP full day conference yielded 69 responses; 52 were received with initial mailing (46\%), and 17 additional surveys were returned with follow up mailing, for an overall $60 \%$ response rate. Thirty three respondents were physicians, 22 registered nurses, 10 genetic counsellors, two PhDs not otherwise specified, and two were clinicians who did not indicate their specialty. Overall, $78 \%$ of respondents indicated that their awareness of issues related to cancer genetics improved; $85 \%$ indicated that the information was applicable to their work; $77 \%$ of respondents used course information and referral guidelines to counsel patients about risk or to refer patients for further risk assessment; and $80 \%$ shared the

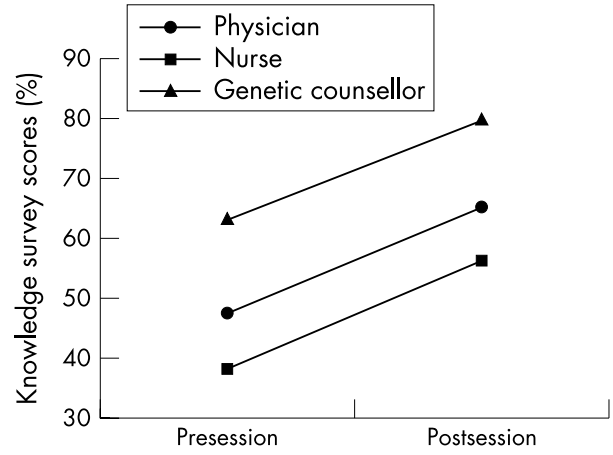

Figure 1 Comparison of cancer genetics knowledge scores by healthcare discipline before and after cancer genetics educational sessions.

information with other clinicians, indicating dissemination of information beyond the conference participants.

Response by profession (MDs, registered nurses and genetic counsellors) to items addressing impact on clinical practice is illustrated in fig 2. Ninety one percent of MDs found the information applicable to their work, and 85\% reported using the information to counsel or refer patients for cancer risk assessment. While a similar percentage of registered nurses (82\%) and genetic counsellors (80\%) reported that cancer genetics was applicable to their work, $64 \%$ of registered nurses reported using the information to counsel and refer patients, compared with $80 \%$ of genetic counsellors. MDs and registered nurses were more likely than genetic counsellors to share the information with other clinicians ( $81 \%$ and $86 \%$, respectively). These differences are probably related to differences in clinical setting and focus among disciplines, and distinctions in the profiles and needs of patients most frequently seen. A subset of respondents $(38 \%)$ reported changes in their referral practice, with several reporting referral of $1-12$ patients for cancer risk assessment in the 11 month interim since the conference. An increase in both the number and appropriateness of referrals to the Cancer Screening and Prevention Program was also noted after delivery of lectures and courses. Although formal referral tracking was not performed, a majority of referrals were directly linked to institutions where CGEP lectures were conducted. This was especially evident after the delivery of one hour lectures to the programme's satellite clinic sites, where lectures are delivered as a progressive series over time. This approach reinforces basic cancer genetics concepts, while broadening the participants' practical understanding of cancer genetics concepts and syndromes.

\section{Program assessment and satisfaction}

Postcourse participant assessments demonstrated satisfaction with the content and delivery of the CGEP curriculum and a high perceived relevance of the information to participant practice, averaging 4.5 on a scale of $1-5$ ( $5=$ highly satisfied, $1=$ not satisfied $)$. Of note, physician

Table 3 Summary of cancer genetics knowledge outcomes before and after educational session, among participants of the cancer genetics education programme (CGEP)

\begin{tabular}{llllll}
\hline Delivery Format* & $\begin{array}{l}\text { Sessions } \\
\text { evaluated }\end{array}$ & $\begin{array}{l}\text { Participants with } \\
\text { complete data }\end{array}$ & $\begin{array}{l}\text { Pre-course } \\
\text { knowledge }\end{array}$ & $\begin{array}{l}\text { Postcourse } \\
\text { knowledge }\end{array}$ \\
\hline One hour lectures & 25 & 312 & $40 \%$ & $\begin{array}{l}\text { Knowledge } \\
\text { improvement }\end{array}$ \\
Full day conference & 6 & 398 & $48 \%$ & $59 \%$ & $48 \%(p<0.001)$ \\
Total & 31 & 710 & $45 \%$ & $66 \%$ & $38 \%(p<0.001)$ \\
\hline
\end{tabular}




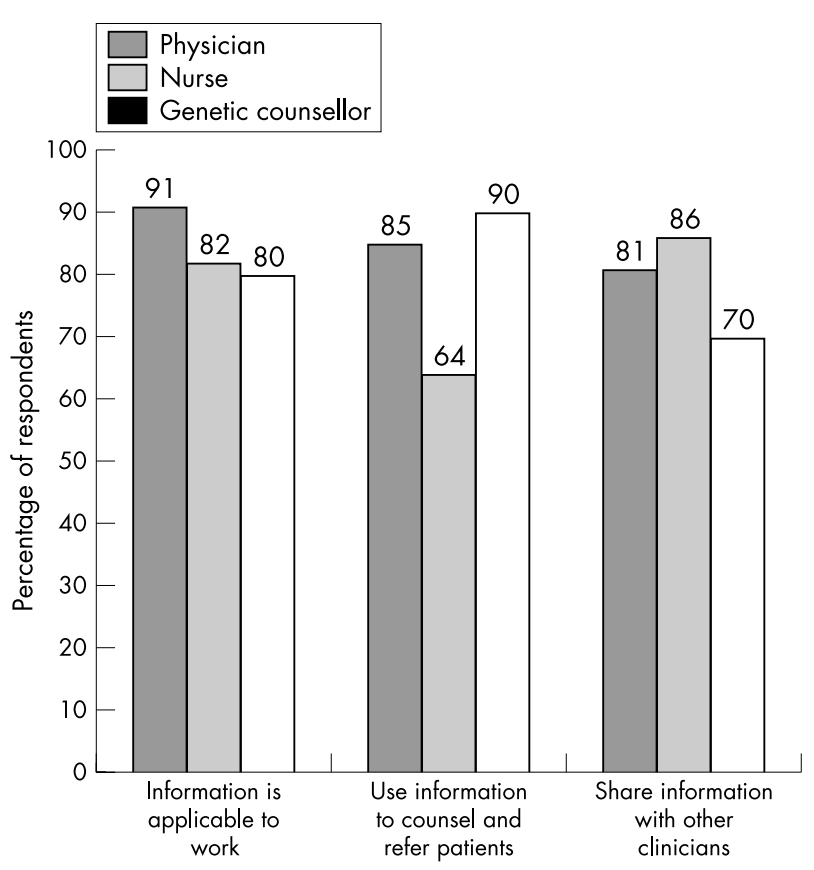

Figure 2 Clinical impact of cancer genetics education on the practices of community based clinicians.

attendance was greatest for the full day conference that provided education on hereditary cancer risk as part of a curriculum covering advances in the full spectrum of cancer risk and risk management (table 2, 2001), reflecting the value of tailoring the course content to address the broader interests of primary care clinicians. Eighty two percent of respondents to the postcourse impact survey indicated that they would be interested in learning more about cancer genetics and cancer risk assessment; $84 \%$ of these indicated a preference for live format, while $16 \%$ preferred to obtain continuing medical education cancer genetics education through CD-ROM or web based distance learning. Respondents indicated interest in topics that would keep them current with evolving cancer genetics technology and advances in cancer prevention and risk management.

\section{DISCUSSION}

As advances in understanding the genetic mechanisms of cancer generate new technologies for risk assessment, ongoing educational resources will be needed to help health care professionals fulfil their roles as gatekeepers to the delivery of cancer risk assessment services. Community clinicians are an important audience for cancer genetics education, as many have limited knowledge on the topic, yet they often serve as the principle source of health information and healthcare access for their patients.

Despite questions regarding the effect of the traditional continuing medical education lecture format on change in physician behaviour ${ }^{40}$ continuing medical education curricula that incorporate case based learning, repetitive or progressive curriculum, and small group sessions with interactive elements do appear to impact changes in practice. ${ }^{34}{ }^{41}$ Our preliminary outcomes suggest that employing the use of established continuing medical education mechanisms to deliver lectures with evidence based content and case based participant interaction does impart increased cancer genetics knowledge and subsequent changes in practice. Furthermore, our findings suggest that health care professionals perceive cancer genetics knowledge to be relevant to their practices, and that both one hour and full day live continuing medical education formats are of value to reach a broad audience of clinicians with diverse educational interests and needs.

It is important that cancer genetics education focus on outcomes related to change in both knowledge and clinician practice, as measured by appropriate referral of patients for cancer risk assessment and dissemination of cancer genetics information to their patients and professional colleagues. In our programme, sampling of knowledge metrics and long term practice impact was limited due to logistics, time constraints, and participant privacy issues, particularly for one hour lecture outreach venues. In the community hospital grand rounds setting, clinicians often arrived late or left lectures early, resulting in partially completed sets of survey data, while the level of participation in knowledge surveys was consistently high for attendees of full day conferences. Although it was difficult to obtain a representative sampling of participants in community hospital grand rounds venues, these participants represented a more diverse spectrum of practitioners as compared with attendees of full day conferences, who are more likely to be self selected by a specific interest in the topic. Nevertheless, the positive increment in knowledge was similar for both settings.

While it was not possible to determine precisely the relationship between the educational intervention and subsequent referral of patients, an estimated $70 \%$ of MDs from our patient referral base have attended one or more of our continuing medical education lectures or full day conferences. We have also observed that once physicians begin to refer patients, they continue to make referrals. This finding may be due in part to the confidence gained through deliberative practice and to learning reinforcement attained through the evidence based risk management recommendations in all clinical consultation notes copied to these clinicians. Metrics on knowledge changes and changes in referral patterns of continuing medical education participants can be improved through streamlined knowledge surveys and by eliciting volunteer participation in long term practice impact surveys.

The continuing medical education mechanism has the potential to complement the emerging body of literature and other educational resources related to cancer genetics risk assessment by presenting complex information in a manner that is relevant to the general practitioner or specialist in the clinical setting. Targeted continuing medical education that incorporates evidence based content and case based learning should lead to better identification and care of individuals with increased cancer risk. Ongoing efforts by the City of Hope Cancer Genetics Education Program include outreach to clinicians practicing in underserved communities and managed care plan utilisation review committees, restructuring the content of full day seminars to include cancer genetics as part of a broader curriculum addressing cancer prevention and control issues of practical utility to primary care physicians, and expansion of the CGEP website to include online continuing medical education accredited learning modules.

\section{ACKNOWLEDGEMENTS}

We wish to thank Alejandra Wright, Bernadette Pabillare, and Alexandra Arad for assistance with programme coordination, data collection, and manuscript preparation.

\section{Authors' affiliations}

K R Blazer, S R Sand, D J MacDonald, J N Weitzel, Department of Clinical Cancer Genetics, City of Hope Comprehensive Cancer Center and Beckman Research Institute, 1500 East Duarte Road, Duarte, CA 91010 
M Grant, Department of Nursing Research and Education, City of Hope Comprehensive Cancer Center and Beckman Research Institute, Duarte S R Sand, Department of Biostatistics, City of Hope Comprehensive Cancer Center and Beckman Research Institute, Duarte

G C Uman, Vital Research, LLC, 8380 Melrose Ave., Suite 309, Los Angeles, CA 90069

The City of Hope Cancer Genetics Education Program is supported in part through the National Cancer Institute (NCl-1R25CA75131), California Cancer Research Program of the University of California \#99-86874, and the DHHS (project MCHG-51 from the Maternal Child Health Bureau). Kaiser Permanente of Southern California and the San Gabriel Valley Chapter of the American Cancer Society provided unrestricted educational grant funds and participated in the Cancer Genetics Education Program advisory board.

Conflicts of interest: none declared.

Correspondence to: K R Blazer, MS, CGC, Assistant Director, Cancer Genetics Education Program, Department of Clinical Cancer Genetics, City of Hope National Medical Center, 1500 E Duarte Road, Module 103, Duarte CA 91010; kblazer@coh.org

Revised version received 15 March 2004

Accepted for publication 16 March 2004

\section{REFERENCES}

1 Burke W, Petersen G, Lynch P, Botkin J, Daly M, Garber J, Kahn MJ McTiernan A, Offit K, Thomson E, Varricchio C for the Cancer Genetics Studies Consortium. Recommendations for follow-up care of individuals with an inherited predisposition to cancer. I. Hereditary nonpolyposis colon cancer JAMA 1997;277:915-9.

2 Burke W, Daly M, Garber J, Botkin JM, Kahn MJ, Lynch P, McTiernan A, Offit K, Perlman J, Petersen G, Thomson E, Varricchio C for the Cancer Genetics Studies Consortium. Recommendations for follow-up care of individuals with an inherited predisposition to cancer. II. BRCA1 and BRCA2. JAMA 1997;277:997-1003.

3 Scheuer L, Kauff N, Robson M, Kelly B, Barakat R, Satagopan J, Ellis N, Hensley M, Boyd J, Borgen P, Norton L, Offit K. Outcome of preventive surgery Oncol 2002;20:1260-8.

4 Hartmann LC, Sellers TA, Schaid DJ, Frank TS, Soderberg CL, Sitta DL, Frost MH, Grant CS, Donohue JH, Woods JE, McDonnell SK, Vockley CW, Deffenbaugh A, Couch FJ, Jenkins RB. Efficacy of bilateral prophylactic mastectomy in BRCA1 and BRCA2 gene mutation carriers. J Natl Cancer Inst 2001;93:1633-7.

5 Kauff ND, Satagopan JM, Robson ME, Scheuer L, Hensley M, Hudis CA, Ellis NA, Boyd J, Borgen PI, Barakat RR, Norton L, Castiel M, Nafa K, Offit K. Risk-reducing salpingo-oophorectomy in women with a BRCA1 or BRCA2 mutation. N Engl J Med 2002;346:1609-15.

6 Rebbeck TR, Lynch HT, Neuhausen SL, Narod SA, Van't Veer L, Garber JE, Evans G, Isaacs C, Daly MB, Matloff E, Olopade OI, Weber BL, and Prevention and Observation of Surgical End Points Study Group. Prophylactic oophorectomy in carriers of BRCA 1 or BRCA2 mutations. N Engl J Med 2002;346:1616-22.

7 Lerman C, Hughes C, Lemon SJ, Main D, Snyder C, Durham C, Narod S, Lynch HT. What you don't know can hurt you: adverse psychologic effects in members of BRCA 1 -linked and BRCA2-linked families who decline genetic testing. J Clin Oncol 1998;16:1650-4.

8 Daly M. NCCN practice guidelines: genetics/familial high-risk cancer screening. Oncology 1999;13:161-83.

9 ASCO. American Society of Clinical Oncology policy statement update: genetic testing for cancer susceptibility. J Clin Oncol 2003;21:2397-406.

10 Fries MH, Holt C, Carpenter I, Carter CL, Daniels J, Flanagan J, Murphy K, Hailey BJ, Martin L, Hume R, Hudson G, Cadman M, Weatherly R, Nunes ME. Guidelines for evaluation of patients at risk for inherited breast and ovarian cancer: recommendations of the Department of Defense Familial Breast/ Ovarian Cancer Research Project. Mil Med 2002;167:93-8.

11 American College of Medical Genetics. Genetic susceptibility to breast and ovarian cancer: assessment, counseling and testing guidelines executive summary. New York: New York State Department of Health, 1999:1-40.

12 McKinnon WC, Baty BJ, Bennett RL, Magee M, Neufeld-Kaiser WA, Peters KF, Sawyer JC, Schneider KA. Predisposition genetic testing for late-onset disorders in adults. A position paper of the National Society of Genetic Counselors. JAMA 1997;278:1217-20.

13 Eng C, Hampel H, de la Chapelle A. Genetic testing for cancer predisposition. Annu Rev Med 2001;52:371-400.

14 Daly MB. Genetic/familial high-risk assessment: breast and ovarian. In: Daly MB, ed. NCCN practice guidelines in oncology. Jenkintown, PA: National Comprehensive Cancer Network, Inc., 2003;Version 1.

15 Watson E, Austoker J, Lucassen A. A study of GP referrals to a family cancer clinic for breast/ovarian cancer. Fam Pract 2001;18:131-4.

16 Myers MF, Doksum T, Holtzman NA. Genetic services for common complex disorders: surveys of health maintenance organizations and academic genetic centers. Genet Med 1999;1:272-85.

17 Menasha JD, Schechter C, Willner J. Genetic testing: a physician's perspective. Mt Sinai J Med 2000;67:144-51.

18 Acton RT, Burst NM, Casebeer L, Ferguson SM, Greene P, Laird BL, Leviton L. Knowledge, attitudes, and behaviors of Alabama's primary care physicians regarding cancer genetics. Acad Med 2000;75:850-2.

19 Wilkins-Haug L, Erickson K, Hill L, Power M, Holzman GB, Schulkin J. Obstetrician-gynecologists' opinions and attitudes on the role of genetics in women's health. J Womens Health Gend Based Med 2000;9:873-9.

20 Hayflick SJ, Eiff MP, Carpenter L. Steinberger J Primary care physicians' utilization and perceptions of genetics services. Genet Med 1998;1:13-21.

21 Koil CE, Everett JN, Hoechstetter L, Ricer RE, Huelsman KM. Differences in physician referral practices and attitudes regarding hereditary breast cancer by clinical practice location. Genet Med 2003;5:364-9.

22 Reynolds PP, Benkendorf JL. Genes and generalists: why we need professionals with added competencies. West J Med 1999;171:375-9.

23 Calzone KA, Jenkins J, Masny A. Core competencies in cancer genetics for advanced practice oncology nurses. Oncol Nurs Forum 2002;29:1327-33.

24 Stopfer JE. Genetic counseling and clinical cancer genetics services. Semin Surg Oncol 2000;18:347-57.

25 Gramling R, David S. Genetic susceptibility to breast cancer: teaching points. Fam Med 2003:35:466-8.

26 Hampel H, Sweet KM, Westman JA, Offit K, Eng C. Referral for cancer genetics consultation: a review and compilation of risk assessment criteria. J Med Genet 2004;41:81-91.

27 Sweet KM, Bradley TL, Westman JA. Identification and referral of families at high risk for cancer susceptibility. J Clin Oncol 2002;20:528-37.

28 Gray RE, Chart P, Carroll JC, Fitch MI, Cloutier-Fisher D. Family physicians' perspectives on ovarian cancer. Cancer Prev Control 1999;3:61-7.

29 Allen HJ. Genetic protocols review by Institutional Review Boards at National Cancer Institute-designated cancer centers. Genet Test 1998;2:329-36.

30 Schroy PC 3rd, Barrison AF, Ling BS, Wilson S, Geller AC. amily history and colorectal cancer screening: a survey of physician knowledge and practice patterns. Am J Gastroenterol 2002;97:1031-6.

31 Freedman AN, Wideroff L, Olson L, Davis W, Klabunde C, Srinath KP, Reeve BB, Croyle RT, Ballard-Barbash R. US physicians' attitudes toward genetic testing for cancer susceptibility. Am J Med Genet 2003;120A:63-71

32 Reilly P. Physician responsibility in conducting genetic testing. J Natl Cancer Inst Monogr 1995;(17):59-61.

33 Wideroff L, Freedman AN, Olson L, Klabunde CN, Davis W, Srinath KP, Croyle RT, Ballard-Barbash R. Physician use of genetic testing for cancer susceptibility: results of a national survey. Cancer Epidemiol Biomarkers Prev 2003;12:295-303.

34 Slotnick HB. How doctors learn: the role of clinical problems across the medical school-to-practice continuum. Acad Med 1996;71:28-34.

35 Korf BR. Medical education in the 'postgenomic era'. How will genetics information be disseminated and integrated? Postgrad Med 2000;108:15-8.

36 American Society of Clinical Oncology. Resource document for curriculum development in cancer genetics education. J Clin Oncol 1997;15:2157-69.

37 American Society of Clinical Oncology. Cancer genetics and cancer predisposition testing. ASCO Curriculum. Alexandria, VA: American Society of Clinical Oncology, 1998;1, 2.

38 Blazer KR, Grant M, Sand SR, MacDonald DJ, Choi JJ, Nedelcu RA, Weitzel JN. Development of a cancer genetics education program for clinicians. J Cancer Educ 2002; 17:69-73.

39 Dillman DA, Christensen JA, Carpenter EH, Brooks RM. Increasing mail questionnaire response: a four state comparison. Am Sociol Rev 1974; 39:746-55.

40 Davis D, O'Brien MA, Freemantle N, Wolf FM, Mazmanian P, TaylorVaisey A. Impact of formal continuing medical education: do conferences, workshops, rounds, and other traditional continuing education activities change physician behavior or health care outcomes? JAMA 1999;282:867-74.

41 Dixon J. Evaluation criteria in studies of continuing education in the health professions: a critical review and a suggested strategy. Eval Health Prof 1978;1:47-65 